\title{
PUBLICIDADE, ADAPTAÇÃO E TRANSMÍDIA: A COMPOSIÇÃO DA NARRATIVA DO CINEMA INFANTIL BRASILEIRO NO FINAL DA DÉCADA DE 1980
}

\author{
ADVERTISING, ADAPTATION AND TRANSMEDIA: NARRATIVE \\ COMPOSITION OF THE BRAZILIAN CHILDREN CINEMA IN THE \\ LATE 1980s
}

Rafael Jose BONA ${ }^{1}$

\begin{abstract}
Resumo: $\mathrm{O}$ artigo tem como objetivo analisar uma obra infantil cinematográfica nacional, representativa do perfil dos filmes do final da década de 1980: O casamento dos Trapalhões (1988, José Alvarenga Júnior). Os objetivos específicos são: identificar as referências do filme sob a ótica das transposições/adaptações; analisar a publicidade inserida nesse filme; e identificar elementos transmídia na obra. Parte-se do pressuposto que muitos dos filmes do antigo grupo humorístico Os Trapalhões, além de introduzirem os jovens espectadores ao contato com outras obras, também praticavam um exercício publicitário, e se utilizavam de técnicas de transmídia e adaptação. A obra é analisada, principalmente, por meio de conceitos dos autores Seger (2007), Jenkins (2009) e Hutcheon (2013). Como principal resultado, constata-se que a obra faz uma adaptação alusiva a um filme dos EUA dos anos de 1950 (Sete noivas para sete irmãos, dir. Stanley Donen, 1954), insere a publicidade de forma (in)discreta no contexto narrativo e sua principal técnica transmídia está relacionada ao nexo com os personagens da televisão e dos quadrinhos do grupo Os Trapalhões.
\end{abstract}

Palavras-chave: Publicidade. Adaptação. Transmídia. Cinema. Os Trapalhões.

\begin{abstract}
The paper aims to analyze a national children's movie, representative of the profile of films of the late 1980s: $O$ casamento dos Trapalhões (1988, José Alvarenga Júnior). The specific objectives are: to identify the movie references from the point of view of the transposition/adaptation; to analyze the advertising inserted in the movie; and to identify transmedia elements in the work. It is assumed that most of the movies of the former humorous group Os Trapalhões, besides introducing the young spectators to the contact with other works, also practiced an advertising exercise and they used techniques of transmedia and adaptation. The work is analyzed, mainly, through concepts of Seger (2007), Jenkins (2009) and Hutcheon (2013). The results show that the movie makes an allusive adaptation to a US film from the 1950s (Seven brides for seven brothers, Stanley Donen, 1954), inserts advertising into the narrative context (in)discreetly and its main transmedia technique is related to the nexus with the television and comics characters from the group Os Trapalhões.
\end{abstract}

Keywords: Advertising. Adaptation. Transmedia. Cinema. Os Trapalhões.

\section{Introdução}

Em dezembro de 2018, o filme $O$ casamento dos Trapalhões (1988), dirigido por José Alvarenga Júnior, completará 30 anos de seu lançamento. Concebido dentro da lógica da indústria do entretenimento da franquia brasileira de Os Trapalhões, do antigo grupo humorístico formado por Didi, Dedé, Mussum (in memoriam) e Zacarias (in memoriam), parte-se do pressuposto que o filme apresenta uma narrativa que emprega técnicas de publicidade, de transposições/adaptações e de transmídia. O referido filme é uma produção da

\footnotetext{
${ }^{1}$ Doutor em Comunicação e Linguagens (UTP). Docente da Universidade Regional de Blumenau (FURB) e da Universidade do Vale do Itajaí (UNIVALI). E-mail:
}

Revista Graphos, Vol. 20 n. 1, 2018 | UFPB/PPGL | ISSN 1516-1536 
Renato Aragão Produções Artísticas Ltda., ZDM, Columbia Pictures e Art Films, com argumento de Renato Aragão, roteirizado por Mauro Wilson, Paulo Andrade e Carlos Alberto Diniz. Teve um público de 4.779.029 espectadores nos cinemas e tornou-se um dos filmes mais lucrativos do grupo, sendo a $15^{\mathrm{a}}$ maior bilheteria do cinema nacional até o momento, conforme dados da ANCINE (2018).

Presente em diferentes narrativas de mídia (cinema, televisão, quadrinhos, publicidade, música, etc.), o quarteto se tornou famoso por realizar sátiras do cotidiano, transpor histórias famosas da literatura e do cinema por meio de paródias a diversas situações e narrativas, desde telenovelas até filmes campeões de bilheteria.

O cinema do grupo possuía uma narrativa antropofágica, que buscava muito de sua inspiração em fontes da cultura estrangeira, para construir suas próprias criações e uma maneira única de produzir histórias derivadas de outras. Histórias essas que foram transformadas, imitadas, aludidas, entre outras formas, conduzidas para uma narrativa concebida sob várias vozes, num diálogo intenso com a indústria cultural (LUNARDELLI, 1996).

Dentro desse contexto este artigo tem como objetivo analisar o filme $O$ casamento dos Trapalhões. Os objetivos específicos são: identificar as referências do filme sob a ótica das adaptações; analisar a publicidade inserida nesse filme; e identificar elementos transmídia na obra.

O filme, objeto de estudo, foi produzido com a política da nova marca de Os Trapalhões, quando se iniciou uma renovação e unificação de seus produtos de mídia a partir do ano de 1987. Naquele período foram produzidos alguns filmes, com uma qualidade diferenciada dos realizados até o momento: com gravações em estúdios cada vez mais sofisticadas e apoios mais explícitos dos anunciantes - a publicidade começou a se tornar mais presente nos filmes por meio do product placement/merchandising - e a aproximação com a linguagem da televisão tornou-se mais invasiva e comum nas narrativas cinematográficas. Ramos (2004) também constata que o filme trabalha com uma estética publicitária que utiliza o cenário e a iluminação e induz a um padrão moderno, típico dos comerciais de televisão da época.

\section{As transposições/adaptações no mundo do entretenimento}

As adaptações sempre foram essenciais para a comunicação midiática, principalmente para o cinema e a televisão. Elas são forças vitais na indústria do entretenimento pois já 
trabalham com um material que possui um público formado e isso contribui na publicidade da nova obra que é criada. Ao se pensar na questão comercial das adaptações elas sempre serão mais rentáveis por serem mais conhecidas entre os atores sociais (SEGER, 2007).

Com o passar dos anos, as adaptações sofreram mudanças, em processos que são repensados e conceituados. Na maioria dos casos, esses processos são comprometidos e direcionados a uma estrutura narrativa especificamente comercial da indústria do entretenimento, deixando-se de lado, por vezes, a qualidade artística da adaptação (SEGER, 2007).

Compreende-se por entretenimento, conforme Castro (2006), toda a linguagem que expressa as ideias, também sentimentos e comportamentos no ritmo da diversão a partir dos produtos de mídia, como filmes cinematográficos, programas de televisão, revistas em quadrinhos, games, entre outros, e que facilitam o consumo.

\footnotetext{
No entanto, é importante lembrar que entretenimento não é só show, mas também negócio, e sendo assim, os produtores precisam estar razoavelmente seguros de que conseguirão obter retorno sobre seus investimentos. Porém, há uma linha tênue entre a atitude de assumir riscos calculados, para que projetos originais sejam produzidos, e a atitude de tomar decisões cautelosas, baseadas no que já foi feito antes para atrair o público (SEGER, 2007, p. 21).
}

Todas as adaptações passam por processos que são realizados de diferentes maneiras e graus de imersão. Alguns gêneros e produtos de mídia utilizam a adaptação para contar histórias (como os livros, romances), outros para mostrá-las (as mídias performáticas), e aquelas que possibilitam a interação física e cinestésica (os games, parques temáticos). Essas três formas de interação possibilitam a compreensão da adaptação a partir de indagações como "o que, quem, por que, como, quando e onde" (HUTCHEON, 2013, p. 15).

Todo processo ou produto de uma adaptação pertence a um contexto temporal, a um local, sociedade e cultura. Ele não existe sem mudanças de valores e significados de uma história para o local em que está se adaptando o produto. Está sempre de acordo com o "engajamento" ou "modo de interação", termo conceituado a partir das três formas de contato com as histórias: contar, mostrar e interagir (HUTCHEON, 2013).

Comparato $(2009$, p. 314) contextualiza a adaptação como sendo uma "transcrição de linguagem que altera o suporte linguístico utilizado para contar a história”. Esse processo pode ser denominado como transubstanciador, no qual se utiliza uma obra e a transforma em outra. A isso também acontece um ato de recriação. Existem vários níveis ou graus de adaptação em que estão sempre em jogo três aspectos da obra original: seus personagens, a 
narrativa da história e o tempo da ocorrência da ação. Isso vai de acordo com o material que é adaptado a partir da recriação do original.

Dentro das perspectivas sobre os processos de adaptação, Comparato (2009) estabelece cinco graus de adaptação: (1) adaptação propriamente dita: é quando se está mais fiel à obra original. Nesse caso, quase não há alterações na história - nem em personagens, no tempo, na localização, entre outros elementos; (2) baseado: quando a obra original é reconhecida a partir de alguns elementos, porém, a história sofre mudanças que vão de personagens e situações. Alguns elementos do original, facilmente reconhecidos pelo público são mantidos na adaptação; (3) inspirado: alguns aspectos do original são mantidos, porém, a história é desenvolvida sob a perspectiva de uma nova estrutura dramática; (4) recriação: quase não há um grau de fidelidade com a obra original. Nesse caso, o autor captura um elemento e o transforma em outra narrativa trabalhando de forma livre na adaptação; (5) adaptação livre: parecida com a apropriação propriamente dita. A história original se mantém, mas é dado um novo ponto de vista, sob determinado aspecto da obra. Entram as particularidades do adaptador em ver, narrar, argumentar e explorar a obra original.

Cabe aqui também mencionar o ato de transcriação, termo cunhado pela Marvel Comics, quando esses se referiam aos processos de reinvenção a partir da adaptação de uma franquia de cinema existente, com objetivo de torná-la mais atrativa para um mercado cultural específico como o projeto de uma história em quadrinhos, e publicada na Índia com o título de: Homem-Aranha: Índia, em 2004 (JENKINS, 2009).

\section{Narrativa transmídia: a expansão das histórias}

A expansão das histórias, com autonomia dos conteúdos e em diferentes plataformas, é conhecida como narrativa transmídia ou transmedia storytelling. O espectador pode ter acesso à obra por meio de qualquer mídia, sem precisar ter o conhecimento de todas as partes. São produzidas histórias com o objetivo de expansão ou retração, a partir de veículos como o cinema, os games, as histórias em quadrinhos, os seriados de televisão, web séries, entre outros. Essas produções, geralmente, estão relacionadas à lógica da indústria do entretenimento que tem, por finalidade, manter um público fiel e consumidor e atrair, cada vez mais, múltiplos grupos de atores sociais, com a adaptação dos conteúdos para cada tipo de meio. Alguns autores como Kinder (1991), Jenkins (2009) e Scolari (2013) são conhecidos por se aprofundarem nos conceitos acerca de estudos sobre transmídia. 
O termo intertextualidade transmídia foi definido por Kinder (1991), ao observar os programas televisivos destinados às crianças e veiculados aos sábados pela manhã, nos Estados Unidos. A autora percebeu que, naquele contexto, elas tinham o primeiro contato com as narrativas e esse era, geralmente, com histórias oriundas do cinema. Muitas vezes, essas histórias eram transpostas para a televisão, para os quadrinhos e para os games, de forma parodiada, reciclada e reconfigurada. As relações intertextuais das narrativas contribuíam para a criação de um novo sentido à obra.

Jenkins (2009) ampliou o sentido de narrativa transmídia, a partir da análise de filmes cinematográficos como os da franquia Star Wars (1977-2005), de George Lucas, e Matrix (1999-2003), de Andy e Lana Wachowski. Conforme Jenkins, esse fenômeno sempre existiu, porém, somente nas últimas décadas, começou a ser conceituado e teorizado sob diferentes perspectivas. A narrativa transmídia se desenrola em múltiplas plataformas, com a função de expandir uma história, por meio de seus personagens ou enredos.

A narrativa transmídia proporciona uma expansão que é concebida de forma multimodal e se expressa em diferentes meios e linguagens. Trata-se de um fenômeno transversal que está presente na indústria cultural e envolve diferentes profissionais, como os publicitários, os jornalistas, os cineastas, assim como os professores e estudantes da área. Cada mídia tem o poder de contribuir na formação de universos narrativos, de acordo com suas peculiaridades de produção de sentidos (SCOLARI, 2013).

Muitos dos estudos sobre transmídia, na contemporaneidade, estão relacionados à convergência midiática proporcionada pela rede mundial de computadores. Entretanto, de acordo com Jenkins (2009) e Scolari (2008), o sentido de convergência que a interatividade tornou possível só é entendido e aplicado na contemporaneidade, devido ao surgimento da internet. $\mathrm{Na}$ época em que Os Trapalhões faziam sucesso, praticamente não existiam computadores nos lares brasileiros e uma das suas melhores exposições na mídia era a televisão, que colaborava para despertar o interesse no consumo de outras de suas narrativas, em meios diferentes como o cinema, as histórias em quadrinhos, a publicidade, entre outros, o que concebia a narrativa transmídia do grupo (BONA, 2016).

\section{A publicidade e Os Trapalhões}

A publicidade tem como peculiaridade trazer ao público informações sobre os produtos ou serviços, de uma forma sedutora e persuasiva. Nela existem regras de combinação de signos, tendo a possibilidade, assim como em qualquer outro universo de discurso, de manter 
um intertexto com outros discursos da sociedade (TRINDADE, 2012). A narrativa publicitária se refere à vida do produto ou serviço a ser consumido pelos atores sociais a partir de uma lógica de consumo que englobam desejos e prazeres que trabalham no imaginário. $\mathrm{O}$ discurso publicitário é uma espécie de "magia" que se faz "presente por meio das narrativas em palavras, imagens, cores, movimentos e todos outros recursos proporcionados pela mídia" (CASTRO, 2006, p. 119).

O efeito de um anúncio publicitário, seja ele em mídia impressa ou eletrônica, é o de convencer um determinado público a comprar um produto ou serviço de alguma empresa. Esse público pode ser o adulto ou o infantil e, às vezes, criam-se conflitos familiares quando os pais resistem a adquirir um produto para a criança. Isso afeta atitudes e valores relacionados ao consumo, à questão financeira e à aparência. Para que o efeito de um anúncio publicitário ocorra são investidos milhões em publicidade anualmente, no mundo todo. Essa comunicação publicitária pode vir na forma da criação de personagens relacionados à marca, promover a lealdade a ela, despertar o desejo, incentivar o consumo e influenciar até na orientação de valores (STRASBURGER; WILSON; JORDAN, 2011).

A comunicação publicitária foi uma oportunidade para o grupo Os Trapalhões, embalado por sua alta popularidade, ainda nos anos de 1970, quando começou uma série de inserções publicitárias durante os seus programas. "Marcas como Hering, Biotônico Fontoura e Marisol foram trazidas pelo amigo e empresário João Batista Sérgio Murad, mais tarde famoso pelo personagem Beto Carrero" (BARRETO, 2014, p. 177). Ele tinha uma carreira de publicitário e conseguiu crescer no mercado aliando a televisão com celebridades para alavancar vendas de determinadas marcas ou produtos. A parceria com Beto Carreiro foi essencial para o ramo publicitário de Os Trapalhões. Isso garantiu os recursos para os investimentos em filmes cinematográficos do quarteto. Um dos maiores problemas enfrentados na questão publicitária foi quando o grupo se desfez em 1983. O acordo com Aragão, Murad e a TV Globo rendeu muito nas vendas de produtos que o grupo divulgava como a marca Monange, as bicicletas Monark e o Biotônico Fontoura (BARRETO, 2014).

Realizar filmes no Brasil, principalmente entre os anos de 1970 e de 1980, era desafiador. Renato Aragão (o Didi) chegou a pedir empréstimo para a Embrafilme, empresa do Governo Federal, para realizar Os Trapalhões no planalto dos macacos (1976), e teve que realizar um product placement indiscreto. "O nome, o logotipo e os ônibus da Viação Itapemirim, apoiadora da fita, aparecem em diversas cenas, inclusive como patrocinadora do balão que faz a viagem interplanetária" (BARRETO, 2014, p. 182). O product placement iria continuar nos próximos filmes. A Viação Itapemirim esteve presente em $O$ Trapalhão nas 
minas do rei Salomão (1977). "Se o brasileiro médio tinha dificuldades para comprar carne para se alimentar, imagine o custo e as dificuldades de manter uma equipe de produção, alugar equipamentos e ainda pagar elenco, direção, locações...” (id., p. 199). Por ter muito investimento do Governo Brasileiro nos filmes, locações de películas como Os três mosquiteiros Trapalhões (1980), por exemplo, "fez propaganda das belezas naturais de Manaus, Foz do Iguaçu e do Rio de Janeiro sob encomenda do governo” (id., p. 226), assim como, havia a insistência do Governo para propagar o programa Pró-Álcool.

Em suma, com o alto investimento nas produções de seus filmes, principalmente depois do ano de 1987, o grupo começou a investir maciçamente nas estratégias publicitárias como o product placement, que gerava muitas críticas ao cinema do grupo. A partir de toda a exposição conceitual teórica, parte-se para os procedimentos metodológicos do texto que conduziram para a análise fílmica proposta.

\section{Procedimentos metodológicos}

A pesquisa se classifica como documental, de abordagem qualitativa e utiliza como técnica a análise fílmica. Aumont e Marie (2011) esclarecem que assim como não há uma teoria única para o cinema, também não há uma única teoria para realizar uma análise fílmica. Dessa forma, optou-se por utilizar a forma de análise dos autores que estabelecem o filme como uma obra de arte autônoma. Nessa forma de análise são encontrados elementos textuais, estruturas narrativas, imagens e sons que podem produzir efeitos específicos no espectador.

É importante esclarecer, conforme Vanoye e Goliot-Lété (2012, p. 51), que todo "filme é um produto cultural inscrito em um determinado contexto sócio-histórico". Mesmo que o cinema possua certa autonomia em relação às demais artes, como a televisão, por exemplo, os filmes não devem ser isolados de outros contextos da sociedade em que eles foram concebidos. Isso se relaciona a questões de mercado, de técnicas, de ciências, de outras artes. Portanto, a análise também leva em conta o contexto (político, social, cultural, etc.) de quando ele foi produzido e lançado. O filme foi assistido duas vezes e descrito em forma de texto no qual são identificados elementos das adaptações, da transmídia e da publicidade. Os conceitos dos autores expostos na revisão de literatura conduziram para a análise específica desses três elementos na obra fílmica, que se apresenta a seguir. 


\section{Análise de $O$ casamento dos Trapalhões}

A narrativa do filme gira em torno dos quatro Trapalhões, que nesta história são irmãos e moram em uma fazenda. Em determinado momento, Didi vai para cidade grande e conhece Sônia (Nádia Lippi), por quem se apaixona e se casa no dia seguinte. Os demais irmãos vão para uma festa na cidade com o novo casal e conhecem mais três mulheres. Nesse meio tempo, a irmã deles escreve dizendo para tomarem conta dos quatro sobrinhos, que são os integrantes do grupo musical Dominó (uma banda famosa de rapazes dos anos de 1980 e 1990), e pede que passem uns dias no interior. Todos eles conhecem outras garotas e vivem confusões na fazenda, além de enfrentar o vilão Expedito (José de Abreu). No final, todos acabam se casando e indo para a fazenda.

O filme inicia com uma abertura (vinheta), apresentando os personagens dos quadrinhos do grupo (editora Abril) em desenhos animados. Na narrativa da vinheta, os personagens do quarteto acabam de acordar. Um galo usa uma conguinha e canta, e eles começam a se arrumar para o dia que recém começou. A inserção do produto conguinha de Os Trapalhões aparece na cama com os personagens, ao lado dela. É o primeiro momento em que a publicidade se faz presente. Os créditos com o título do filme (além dos dados da produção técnica) aparecem. Em seguida, o grupo faz trapalhadas ainda dentro de casa: da escovação de dentes do Dedé ao grupo na cozinha tomando café da manhã. É o momento também em que Didi começa a calçar o sapato (a conguinha) e fica espantado com a quantidade de coisas que cabem dentro dela. Isso faz uma alusão às qualidades enfatizadas em relação ao produto que estava disponível para venda no mercado (ver figuras 1 a 3).

Figura 1 - Still-frame de $O$ casamento dos Trapalhões (1988)

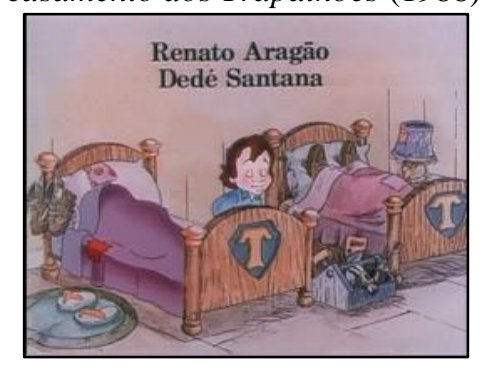

Fonte: recorte do autor.
Figura 2 - Still-frame de $O$ casamento dos Trapalhões (1988)

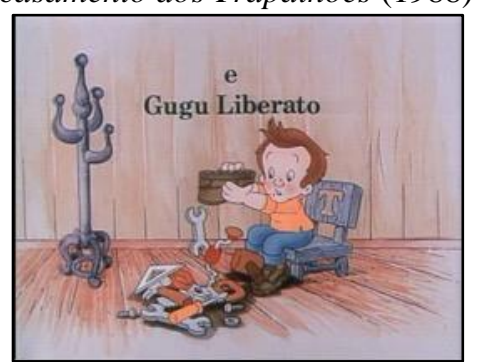

Fonte: recorte do autor.
Figura 3 - Still-frame de $O$ casamento dos Trapalhões (1988)

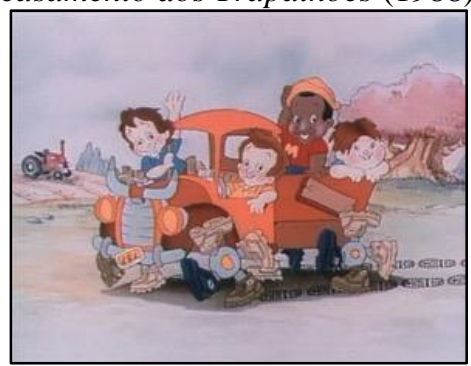

Fonte: recorte do autor.

Na referida vinheta, os três atos de uma narrativa clássica são apresentados: o início do dia, os afazeres, o problema com a camionete e a solução, e eles indo para a cidade. Os personagens, por serem os mesmos dos quadrinhos, mais remetem aos quadrinhos do que aos personagens interpretados por eles no filme, assim como o figurino. Não há diálogo entre os 
personagens, mas a música que embala a narrativa condiz com o "contexto" caipira, e os ruídos estão sempre de acordo com o barulho dos animais ou das ações dos personagens. A vinheta de abertura, além de se configurar como uma técnica publicitária, é um exemplo funcional de nexo narrativo com os personagens das histórias em quadrinhos do grupo. A vinheta colabora para uma espécie de propagação e formação de conceitos de consumos da marca do grupo. A narrativa fílmica propiciava ao público a experiência de acompanhar o quarteto da televisão nas telas do cinema e, ao mesmo tempo, reforçava o consumo dos personagens das histórias em quadrinhos. Essa técnica pode ser constatada como transmídia por possibilitar o nexo com demais personagens que fazem parte do universo narrativo do grupo.

A produção do filme carrega uma quantidade de artistas famosos da mídia, na época, como a atriz de telenovelas, Nádia Lippi; a modelo e ex-paquita do programa Хои da Хиха (1986-1992), e que recentemente havia posado para a revista Playboy brasileira, Luciana Vendramini, que interpreta Ana; a adolescente Patrícia Lucchesi, que havia ganhado notoriedade por estrelar um comercial de televisão de sutiã da marca Valisère (em 1987), que interpreta Denise; além do apresentador Gugu Liberato e o grupo musical Dominó que interpretam eles mesmos.

Os Trapalhões não mudam de nomes, mas suas identidades são voltadas para uma versão caipira, em que eles moram na fazenda e realizam tarefas rurais. Há uma forte carga dos trejeitos, risadas, pontapés, peidos, cambalhotas e vários elementos da comédia pastelão em diversos momentos do filme, apesar de ser tratado um tema sério como o casamento. A comédia pastelão, conhecida nos Estados Unidos como slapstick (slap: bofetada, stick: bastão) se refere àquela em que há sincronia da atuação do ator com as risadas do público. As piadas jocosas, os flertes com a esposa do amigo, as bofetadas, os gestos extrapolados, as tortas na cara e a linguagem circense, contribuem para a consolidação desse subgênero. Teve início, nos Estados Unidos, com filmes do ator Charles Chaplin (1889-1977), e foi propagado também pelos filmes de $O$ gordo e o magro (famosos entre as décadas de 1920 e de 1930) e Os três patetas (1922-1970).

No filme, há várias provocações de riso, quando Zacarias inicia uma conversa com as plantas e os animais e faz um pequeno casamento de um galo e uma galinha e os veste a caráter. Mussum está sempre à procura de bebida alcóolica e sempre que tem a oportunidade está a beber, continuamente utilizando o "is" nos finais das frases (característica de seu personagem). Dedé continua fazendo o papel de escada dos demais, mas provoca o riso com o uso do corpo, com tombos e trejeitos engraçados. Didi é o que conduz a narrativa. Apesar de 
ter trejeitos engraçados, ele também é um personagem de porte mais agressivo. Porém, em todo o filme, há muitas piadas e trocadilhos, mas esse cenário é mais evidente no início da narrativa.

O filme tem uma fotografia diferente de todos os outros produzidos até então por utilizar câmeras mais ágeis e novos cenários. Em quase todos os momentos em que $O s$ Trapalhões estão na cidade, há um deslocamento não somente dos personagens, mas de toda a atmosfera do filme, que passa de um tom marrom para um de azul e vermelho psicodélico (ver figuras 4 a 6 ).

Figura 4 - Still-frame de $O$ casamento dos Trapalhões (1988)

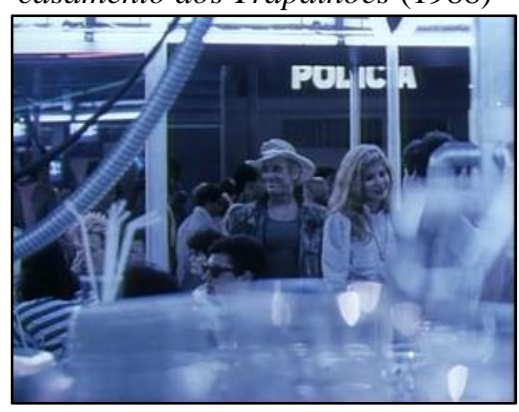

Fonte: recorte do autor.
Figura 5 - Still-frame de $O$ casamento dos Trapalhões (1988)

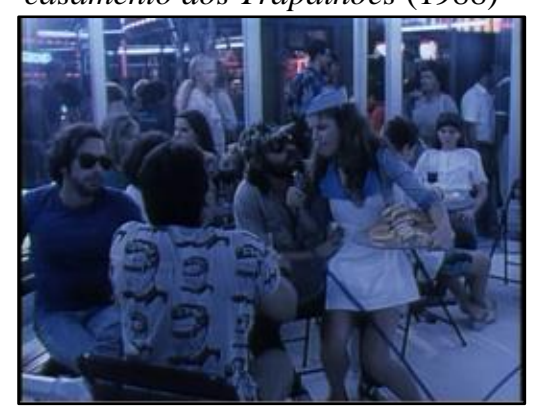

Fonte: recorte do autor.
Figura 6 - Still-frame de $O$ casamento dos Trapalhões (1988)

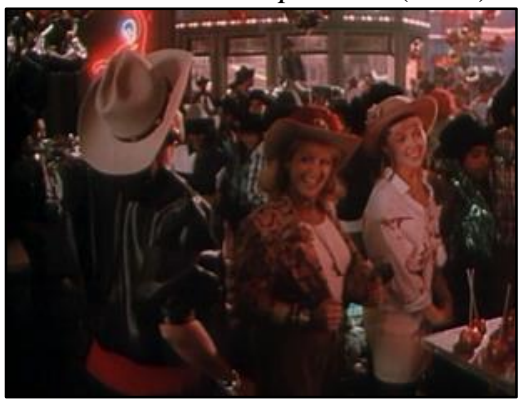

Fonte: recorte do autor.

Há um momento memorável do trio - Dedé, Mussum e Zacarias - que, ao chegarem pela primeira vez na cidade, encontram uma vitrine com vários televisores à mostra e eles se maravilham com o que veem. Começam a imitar os trejeitos que são exibidos na televisão de forma encantadora e simbólica. É um caso típico para demonstrar o poder comunicacional e fascinante que a linguagem da televisão tinha naquela época. Uma cena que se torna cômica, pois, até então, eram os "heróis da televisão" que estavam espantados com o que o público via na televisão (ver figuras 7 e 8 ).

Figura 7 - Still-frame de $O$ casamento dos Trapalhões (1988)

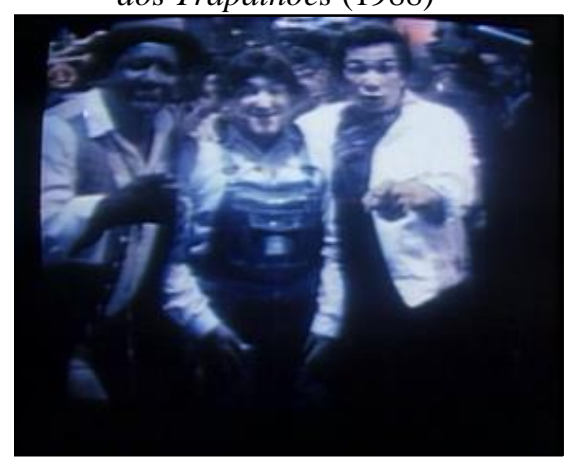

Fonte: recorte do autor.
Figura 8 - Still-frame de $O$ casamento dos Trapalhões (1988)

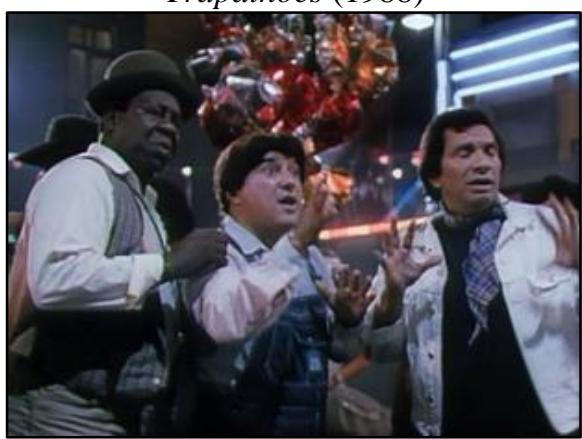

Fonte: recorte do autor. 
Apesar de ser um filme com bastante cenas de violência e agressões - algo que ocorre em muitos momentos, com lutas corporais, desordem e tiros - se passa uma mensagem sobre valores de união entre o homem e a mulher, além de questões relacionadas à importância do homem do campo, da vida na fazenda, de como é importante para a alimentação. Didi deixa claro, desde o início, que todo homem precisa de uma companheira, mas ao mesmo tempo, esta sempre é vista como uma pessoa que vai fazer trabalhos domésticos. No primeiro momento em que ele vê Joana, se apaixona por ela. Porém, Joana trabalha e realiza serviços numa lanchonete na cidade.

A história de $O$ casamento dos Trapalhões é uma adaptação em formato parodiado do filme Sete noivas para sete irmãos (Stanley Donen, 1954), clássico musical de comédia dos anos de 1950. Esse tipo de adaptação remete a algo que pode ser chamado aqui de “adaptações transculturais” (HUTCHEON, 2013, p. 196), pelas questões lógicas de mudança de tempo e do lugar e estão associadas às questões regionais e culturais que podem ter sido alteradas conforme o passar do tempo. Assim como para Hollywood transculturalizar uma obra significa americanizá-la (HUTCHEON, 2013), para Os Trapalhões, transculturalizar significa abrasileirá-la. É possível perceber, também, traços de filmes de Amácio Mazzaropi (1912-1981), que teve importante trajetória no audiovisual brasileiro ao levar a figura do homem do campo para as telas do cinema. Didi também remete a outro personagem famoso no cinema dos anos de 1980, o Michael Dundee (interpretado por Paul Hogan), dos filmes Crocodilo Dundee (Peter Faiman, 1986) e Crocodilo Dundee II (John Cornell, 1988).

Isso está de acordo com o cenário exposto por Stam (2006, p. 48), quando relata que "as adaptações fazem malabarismos entre múltiplas culturas e múltiplas temporalidades, elas se tornam um tipo de barômetro das tendências discursivas em voga no momento da produção". Toda recriação faz um desmascaramento das facetas não somente da obra e de sua proveniência, mas do momento e da cultura em que aquela adaptação é realizada (STAM, 2006). "A adaptação representa o modo como as histórias evoluem e se transformam para se adequar a novos tempos e a diferentes lugares" (HUTCHEON, 2013, p. 234). E, nesse caso, Os Trapalhões moldaram elementos, principalmente de um filme dos anos de 1950, dos Estados Unidos, para um cenário brasileiro no final dos anos de 1980.

Em relação à publicidade, $O$ casamento dos Trapalhões tem uma quantidade excessiva de product placement que, por vezes, interage ou não com os personagens principais. Os produtos vão desde a marca de refrescos Royal, como as conguinhas do quarteto. Além disso, marcas como as de Beto Carrero, Lâmpadas Osram, Staroup, refrigerante Pepsi, Viação Gato Preto, iogurte Dan’Up, entre outras, estão presentes. Em dois momentos do filme, produtos 
ganham vida e interagem com os personagens: a mascote Bocão, da marca Royal, e uma conguinha de Os Trapalhões em formato gigante (ver figuras 9 a 11). Há, portanto, interações discretas e indiscretas da publicidade em toda a narrativa fílmica.

Figura 9 - Still-frame de $O$ casamento dos Trapalhões (1988)

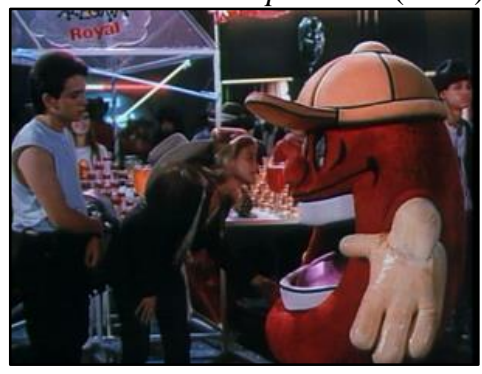

Fonte: recorte do autor.

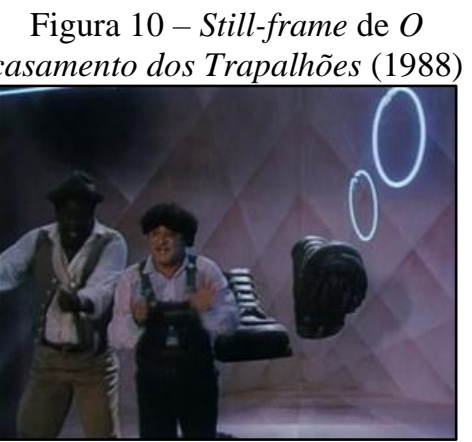

Fonte: recorte do autor.
Figura 11 - Still-frame de $O$ casamento dos Trapalhões (1988)

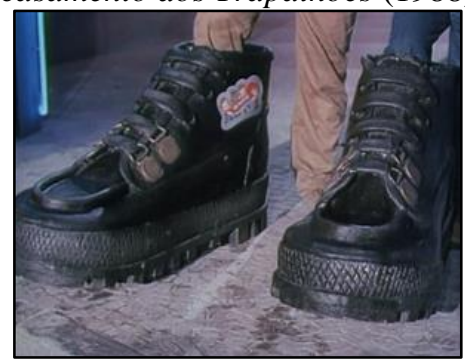

Fonte: recorte do autor.

O filme termina com Didi e Joana voltando para casa numa camionete. Na parte de trás do automóvel aparecem os demais personagens com suas companheiras e vestidos de noivos. Os créditos sobem e iniciam as imagens com erros de gravação e bastidores da produção, em uma prática de metalinguagem.

Em suma, todo o universo do filme faz um exercício de adaptação (por aludir diretamente a uma obra clássica do cinema estadunidense, além de fazer alusões a diferentes contextos), colabora também para um intenso exercício de publicidade (por meio do product placement utilizado em grande quantidade durante a narrativa), e de transmídia, por possibilitar o nexo com os personagens da televisão. Conforme Jenkins (2009), a narrativa transmídia possibilita a expansão das histórias e dos personagens para outras plataformas (nesse caso, das narrativas da televisão para o cinema, além de propiciar o contato com os personagens das histórias em quadrinhos na vinheta de abertura do filme).

\section{Considerações finais}

$\mathrm{O}$ artigo teve como objetivo realizar uma análise fílmica descritiva de $O$ casamento dos Trapalhões; e os objetivos específicos foram: identificar as referências do filme sob a ótica das adaptações; analisar a publicidade inserida nesse filme; e identificar elementos transmídia na obra.

Como principal resultado, constata-se que o filme faz uma adaptação alusiva ao filme Sete noivas para sete irmãos (1954, Stanley Donen), clássico musical de comédia dos anos de 1950. Mesmo que o principal público do quarteto, as crianças, não (re)conheçam a adaptação 
alusiva, o filme se torna uma porta de entrada para outras leituras intertextuais entre os meios de comunicação que dialogam com os programas de televisão - com a participação do apresentador Gugu Liberato, com artistas da música (grupo musical Dominó) e com uma série de product placement que incentiva o consumo dos produtos exibidos no filme. A publicidade é inserida de forma (in)discreta no contexto narrativo e a principal técnica transmídia do filme está relacionada ao nexo com os personagens da televisão e dos quadrinhos (por meio da vinheta de abertura do filme).

Estudar o cinema infantil brasileiro oriundo de artistas da televisão, do passado, contribui para o entendimento de como se configurava a linguagem cinematográfica influenciada, quase que em sua totalidade, pela televisão, pela publicidade e por meio de técnicas transmídia. Deixa-se de sugestão para outros estudos, uma análise de filmes oriundos de artistas da televisão, dos anos de 1980 e 1990, como Xuxa Meneghel e Angélica, que igualmente faziam parte do cenário midiático nacional semelhante ao grupo Os Trapalhões.

\section{Referências}

ANCINE. Agência Nacional do Cinema. Disponível em: <https://www.ancine.gov.br>. Acesso em: 25 jul. 2018.

AUMONT, J.; MARIE, M. A análise do filme. Trad.: Marcelo Félix. Lisboa: Edições Texto \& Grafia, 2011.

BARRETO, J. Mussum forévis: samba, mé e Trapalhões. São Paulo: Leya, 2014.

BONA, R. J. Os Trapalhões e a comunicação midiática: a concepção de uma narrativa transmídia made in Brazil. 199 p. Tese de Doutorado (Comunicação e Linguagens) Universidade Tuiuti do Paraná (UTP), Curitiba, 2016.

CASTRO, V. J. A publicidade e a primazia da mercadoria na cultura do espetáculo. In.:

COELHO, C. N. P.; CASTRO, V. J. (Orgs.). Comunicação e sociedade do espetáculo. São Paulo: Paulus, 2006. p. 109-127.

COMPARATO, D. Da criação ao roteiro: teoria e prática. São Paulo: Summus, 2009.

HUTCHEON, L. Uma teoria da adaptação. Trad.: André Cechinel. 2a ed. Florianópolis: Ed. da UFSC, 2013.

JENKINS, H. Cultura da convergência. Trad.: Susana Alexandria. $2^{\mathrm{a}}$ ed. São Paulo: Aleph, 2009.

KINDER, M. Playing with power in movies, television, and video games: from Muppet Babies to Teenage Mutant Ninja Turtles. California (USA): University of California Press, Ltd, 1991. 
LUNARDELLI, F. Ô psit! O cinema popular dos Trapalhões. Porto Alegre (RS): Artes e Ofícios, 1996.

RAMOS, J. M. O. Cinema, televisão e publicidade: cultura popular de massa no Brasil nos anos 1970-1980. $2^{\text {a }}$ ed. São Paulo: Annablume, 2004.

SCOLARI, C. A. Hipermediaciones: elementos para una teoría de la comunicación digital interactiva. Barcelona: Editorial Gedisa, 2008.

Narrativas transmedia: cuando todos los medios cuentan. $2^{\mathrm{a}}$ ed. Barcelona: Centro Libros PAPF, 2013.

SEGER, L. A arte da adaptação: como transformar fatos e ficção em filme. São Paulo: Bossa Nova, 2007.

STAM, R. Teoria e prática da adaptação: da fidelidade à intertextualidade. Ilha do Desterro. Florianópolis, n. 51, jul./dez. 2006, p. 19-53.

STRASBURGER, V. C.; WILSON, B. J.; JORDAN, A. B. Crianças, adolescentes e a mídia. $2^{\mathrm{a}}$ ed. Porto Alegre: Penso, 2011.

TRINDADE, E. Propaganda, identidade e discurso: brasilidades midiáticas. Porto Alegre: Sulina, 2012.

VANOYE, F. GOLIOT-LÉTÉ, A. Ensaio sobre a análise fílmica. Trad.: Marina Appenzeller. $7^{\mathrm{a}}$ ed. Campinas, SP: Papirus Editora, 2012.

Recebido em 04/05/2018 Aceito para publicação em 03/07/2018 